\title{
Late presenters among newly diagnosed HIV-infected in Poland in 2006-2008
}

\author{
Karolina A. Pyziak-Kowalska ${ }^{1}$, Marta Dusza ${ }^{2}$, Elżbieta Mularska ${ }^{3}$, Anna Kalinowska-Nowak ${ }^{4}$, \\ Elżbieta Jabłonowska ${ }^{5}$, Grażyna Barałkiewicz ${ }^{6}$, Dorota Bander ${ }^{7}$, Regina B. Podlasin², Joanna Kubicka ${ }^{8}$ \\ ${ }^{1}$ Department of Adults' Infectious Diseases, Medical University of Warsaw, Poland \\ ${ }^{2} \mathrm{IV}^{\text {th }}$ Department, Hospital of Infectious Diseases, Warsaw, Poland \\ ${ }^{3}$ Department of Diagnostics and Therapy of AIDS, Centre for AIDS Diagnostic and Therapy, Chorzow, Poland \\ ${ }^{4}$ Department Infectious Diseases, Jagiellonian University Medical College in Cracow, Poland \\ ${ }^{5}$ Clinc of Infectious Diseases and Hepatology, Medical University of Lodz, Poland \\ ${ }^{6}$ Department of Infectious Diseases, Poznan University of Medical Science, Poznan, Poland \\ ${ }^{7}$ Department of Infectious Diseases and Hepatology, Pomeranian Medical University, Szczecin, Poland \\ ${ }^{8}$ HIV Out-Patient Clinic, Hospital of Infectious Diseases, Warsaw, Poland
}

\begin{abstract}
Introduction: Assessment of incidence and factors associated with late vs. early human immunodeficiency virus (HIV) diagnosis among newly diagnosed patients referred to HIV treatment centres in Poland in the years 2006-2008.

Material and methods: Retrospective analysis of medical records of patients reported from eight regional centres for HIV treatment in Poland in years 2006-2008 was conducted. The study population consisted of 1132 HIV-infected patients newly diagnosed with HIV infection, aged 17 years up. To describe characteristics of this group of patients in terms of clinical and immunological presentation multivariate regression analysis of demographic and epidemiology data including: sex, age, mode of transmission, CD4 T cell count, and viral load at the time of diagnosis was performed.

Results: Among 1132 patients included in the study 564 (49.8\%) were late presenters (LP) according to European consensus definition. In multivariate logistic analysis including sex, age and route of infection, as independent factors, age $(\mathrm{OR}=1.06)$, intravenous drug use $(\mathrm{OR}=2.17$ for IVDU vs. $\mathrm{MSM})$, and heterosexuality $(\mathrm{OR}=2.07$ for $\mathrm{Hx}$ vs. MSM) were risk factors for late testing. The same factors were predictors of advanced HIV disease, as well as unknown route of infection $(\mathrm{OR}=1.77 ; p<0.05)$. However, multivariate regression analysis revealed that only advanced age was an independent factor influencing lower CD4 T cell count and late presentation $(\mathrm{OR}=1.02$ per 1 year of age, $p<0.001)$.

Conclusions: Nearly $50 \%$ of patients were diagnosed after the optimal time for antiretroviral treatment initiation, according to actual European and Polish guidelines. These results strongly point out the necessity of further encouragement toward more frequent and earlier HIV testing.
\end{abstract}

HIV AIDS Rev 2017; 16, 4: 244-250 DOI: https://doi.org/10.5114/hivar.2017.72025

Key words: late presenters, HIV epidemic in Poland, high-risk group for HIV, HIV surveillance system.

Address for correspondence: Dr. Karolina A. Pyziak-Kowalska, Emergency Department, Hospital of Infectious Diseases,

37 Wolska St., 01-201 Warsaw, Poland, phone: +48 502104 475,

e-mail: karolina.pyziak@gmail.com
Article history:

Received: 25.07.2017

Received in revised form: 16.02.2017

Accepted: 09.11.2017

Available online: 30.11 .2017
International Journal of HIV-Related Problems

HIV \& AIDS

$R$ e $v$ i e w 


\section{Introduction}

Despite more than three decades of the human immunodeficiency virus (HIV) epidemic and enormous progress in the treatment of the infection with common access to the highly effective antiretroviral treatment, almost a third of individuals infected with HIV enter a health care system very late in the course of their HIV infection throughout Central and Eastern Europe [1]. This situation has remained unchanged for the last several years without evidence of improvement [2]. Surveillance to identify the exact extent of the problem remains insufficient across Europe.

Currently available highly active antiretroviral therapy (HAART) has dramatically improved the prognosis and survival of HIV infected patients [3]. However, late HIV diagnosis, especially when acquired immune deficiency syndrome (AIDS) defining disease has occurred, constitutes a relevant problem for treatment and leads to individual suboptimal usage of HAART [4-6].

Furthermore, late presenters represent an ongoing and serious challenge to the control of the AIDS pandemic. In a global perspective, HIV late diagnosis perpetuates HIV pandemics, while about $50 \%$ of new sexually transmitted infections are transmitted from persons with early phase of HIV disease [7]. HIV late diagnosis and presentation for care is estimated at about $15-38 \%$ of cases across the Europe [8], and this has serious societal and economic consequences, despite access to universal insurance coverage for complex specialist care [9-11].

Moreover, in the past it was difficult to evaluate the extend of this problem, as there were numerous and diverse definitions of late presentation during the evaluation of collected data (Table 1).

Currently we share one universal definition and, every patient with CD4 $\mathrm{T}$ cell count $<350$ cells/ $\mu$ l and/or AIDS defining illness (ADI) fulfils criteria for being recognised as "late presenter" according to current treatment guidelines for HIV infected adults [12].

Since 1985, when HIV diagnostics was introduced in Poland, the number of newly diagnosed cases of HIV disease and AIDS has kept on increasing, particularly in recent years $[13,14]$.

The problem of late presentation was not widely addressed in Poland. The first Polish data that we present were collected from significant number of Polish patients from different HIV clinics and hospitals in the period 2006-2008.

Therefore, the aim of the present study was to determine the frequency of late presenters among newly diagnosed individuals in the years 2006-2008 using current "late presentation" definition, to compare frequencies of late presentation according to previous definitions and to describe late presenters clinical and immunological characteristics.

\section{Material and methods}

The study population consisted of 1132 HIV-infected, Caucasian patients newly diagnosed with HIV infection, aged 17 years up, reported from eight regional centres for HIV treatment in Poland.

Out of 11 centres, operating during the study period in Poland and invited for the survey, four centres provided data for 2006 and $2007(n=563)$ and eight centres for 2008 $(n=591)$. Foreigners and immigrants as well as patients diagnosed elsewhere were not included. Duplicate records of patients registered in two centres during the analysis period were excluded, with only the earlier record being taken into account.

To evaluate whether the study group was representative of the HIV patient population nationwide, the study data were compared with those registered by the National Health Institute for the same period, i.e. 2006 through 2008.

Data on demographic and epidemiology, including age, sex, mode of HIV transmission (injection drug user - IDUs, heterosexual contact - $\mathrm{Hx}$, male having sex with male MSM, unknown/other - UNK), CD4 T cell count, serum viral load at the time of diagnosis, and the patient's medical history were gathered and analysed.

In terms of the numerous definitions of "late presentation" available at the time of the study the data were initially analysed applying a different set of parameters for late presentation (Fig. 1).

Clinical categories A, B, and C, as data were collected and used in the period 2006-2008, were applied according to revised classification system for HIV infection among adolescents and adults from the year 1993 [15]. In addition, a group of persons with very late presentation and CD4 T cell count under 50 cells/ $\mu$ l were analysed.

The appropriate statistical tests were applied for parametric and non-parametric data using Statistica 7.0 software, with $p$ value under 0.05 considered as clinically significant. Tests used for demographic data included Fisher test, Kruskal-Wallis test, Mann-Whitney $U$-test. Odds ratios were assessed for late presenting risk using as independent factors age, gender, route of infection (IDU, Hx, MSM, and unknown), and univariate and multivariate analyses were performed.

\section{Results}

In total 1132 medical records of newly diagnosed patients were identified. The general characteristic of this group is presented in Table 1. These patients represented $46 \%$ of all patients diagnosed with HIV in Poland during the analysis period. Two hundred and sixty-four persons were recorded in 2006, 290 persons in 2007, and 578 in 2008.

Male gender strongly dominated in the analysed group 911 out of 1132 patients (80.5\%). Median age at HIV diagnosis was 31.3 (IQD 26.8-38.6) years; female patients were younger than male: 30 (IQD 24.6-36.3) and 32 (IQD 27.3-39.1) years, respectively, and the difference was statistically significant ( $p<0.001)$. With respect to the mode of HIV transmission, there were 262 (23.1\%) current or previous IDUs, 498 (44\%) MSM (including bisexual men) and 275 (24.3\%) Hx persons. The route of HIV infection remained unknown for 97 (8.6\%) 
Table 1. Comparison of medium age, CD4 T cell count, and viral load between particular gender, mode of transmission, and late vs. non-late testers. Statistical significance assessed using Mann-Whitney $U$ test

\begin{tabular}{|c|c|c|c|c|}
\hline \multirow[t]{2}{*}{ All groups } & $\begin{array}{c}N \\
(\%)\end{array}$ & $\begin{array}{c}\text { Age (years) } \\
\text { Median (IQD: Q25-Q75) }\end{array}$ & 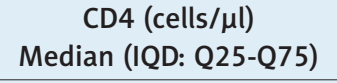 & $\begin{array}{c}\text { VL (copies/ml) } \\
\text { Median (IQD: Q25-Q75) }\end{array}$ \\
\hline & 1132 & $31.3(26.8-38.6)$ & $355(171-530)$ & $30300(5260-110580)$ \\
\hline Female & $221(19.5 \%)$ & $30.5(24.6-36.3)$ & $305(125-503)$ & $19050(2640-75250)$ \\
\hline \multirow[t]{2}{*}{ Male } & $911(80.5 \%)$ & $32(27.3-39.1)$ & $368(185-533)$ & $35000(6020-117000)$ \\
\hline & & $p=0.001$ & $p=0.02$ & $p=0.006$ \\
\hline IDUs & $262(23.1 \%)$ & $31.7(27.7-38)$ & $289(90-504)$ & $31713(6017-106000)$ \\
\hline MSM & $498(44 \%)$ & $30.3(26.1-36.4)$ & $418(265-576)$ & 28555 (6278-103000) \\
\hline $\mathrm{Hx}$ & $275(24.3 \%)$ & $33(26.8-41.9)$ & $282(125-453)$ & 29650 (3890-115000) \\
\hline \multirow[t]{2}{*}{ UNK } & 97 (8.6\%) & $36(24.6-36.3)$ & $364(120-472)$ & 41494 (1456-142500) \\
\hline & & $\begin{array}{c}\text { MSM vs. Hx: } p=0.002 \\
\text { MSM vs. IDUs: } p=0.002\end{array}$ & $\begin{array}{l}\text { IDUs and Hx vs. MSM: } \\
p<0.001 ; \text { IDU vs. Hx: NS }\end{array}$ & NS \\
\hline Clinical category A & 760 & $29.8(25.4-36.5)$ & $461(348-615)$ & $17950(3840-77500)$ \\
\hline Clinical category B & 85 & $34.3(29.0-39.9)$ & $230(134-310)$ & $37100(7240-124000)$ \\
\hline \multirow[t]{2}{*}{ Clinical category C } & 287 & $35.2(30.0-43.9)$ & $65(22-158)$ & $100000(1456-142500)$ \\
\hline & & $\begin{array}{l}\text { C vs. A and B vs. A: } \\
p<0.001 ; \text { B vs. C: NS }\end{array}$ & & $\begin{array}{c}\text { C vs. } B \text { and C vs. A: } \\
\quad p<0.001\end{array}$ \\
\hline CD4 $<50$ cells $/ \mu l$ & 137 & $34.6(30.4-42.5)$ & $20(10-31)$ & $120000(85000-520000)$ \\
\hline \multirow[t]{2}{*}{ CD4 > 50 cells $/ \mu \mathrm{l}$} & 995 & $30.9(28.2-37.9)$ & $398(243-562)$ & $23450(4290-98000)$ \\
\hline & & $p<0.001$ & & $p<0.001$ \\
\hline CD4 $<200$ cells $/ \mu \mathrm{l}$ & 323 & $34.8(30.3-43.9)$ & $64(23-135)$ & $100000(29800-323593)$ \\
\hline \multirow[t]{2}{*}{ CD4 > 200 cells $/ \mu \mathrm{l}$} & 809 & $30.0(25.5-36.7)$ & $452(337-604)$ & $17800(4170-80800)$ \\
\hline & & $p<0.001$ & & $p<0.001$ \\
\hline $\begin{array}{l}\text { CD4 }<200 \text { cells } / \mu l+ \\
\text { clinical category } C\end{array}$ & 363 & $34.8(30.0-43.6)$ & $76(28-160)$ & $100000(27093-279000)$ \\
\hline \multirow[t]{2}{*}{$\begin{array}{l}\text { Other (all without CD4 } \\
<200 \text { + clinical category C) }\end{array}$} & 769 & $29.8(25.3-36.5)$ & $462(348-615)$ & $17000(3865-74300)$ \\
\hline & & $p<0.001$ & & $p<0.001$ \\
\hline CD4 $<350$ cells $/ \mu \mathrm{l}$ & 556 & $34.0(29.4-41.6)$ & $166(51-266)$ & $71750(15609-191000)$ \\
\hline \multirow[t]{2}{*}{ CD4 > 350 cells $/ \mu \mathrm{l}$} & 576 & $29.8(25.3-36.5)$ & $526(434-670)$ & $13100(3122-61200)$ \\
\hline & & $p<0.001$ & & $p<0.001$ \\
\hline $\begin{array}{l}\text { CD4 }<350 \text { cells } / \mu l+ \\
\text { clinical category } C\end{array}$ & 564 & $34.0(29.4-41.5)$ & $170(52-170)$ & 72200 (15609-191000) \\
\hline $\begin{array}{l}\text { Other (all without CD4 } \\
<350+\text { clinical category C) }\end{array}$ & 568 & $29.0(24.7-35.6)$ & $529(435-672)$ & $13056(3100-58400)$ \\
\hline & & $p<0.001$ & & $p<0.001$ \\
\hline
\end{tabular}

NNS - not statistically significant

IDUs - injection drug user, MSM - male having sex with male, Hx-heterosexual contact, UNK - unknown/other

persons. MSMs were significantly younger than IDUs and Hxs ( $p=0.002$ for both).

Median CD4 T cell count at diagnosis was 355 cells/ $\mu \mathrm{l}$ (IQD 171-530) in the whole group. Female patients had significantly lower CD4 T cell count than male; 305 cells/ $\mu \mathrm{l}$ (IQD 125-503) and 368 (IQD 185-533), respectively $(p=0.02)$. Median CD4 T cell counts did not differ statistically between IDUs and Hxs; 289 (125-453) and 282 (125-
453) cells/ $\mu \mathrm{l}$, respectively, but they were significantly higher in MSM - 418 (265-576) cells/ $\mu$ l than in both other groups ( $\mathrm{p}<0.001$ for both). Among IDUs, male patients had significantly lower CD4 T cell count ( 276 cells/ $\mu$ l) than female ones (349 cells/ $\mu$ l) from this group $(p<0.05)$.

Depending on the definition of "late presentation", the incidences for the whole group varied from about $25 \%$ when the category $\mathrm{C}$ was defined to nearly $50 \%$ when the most 


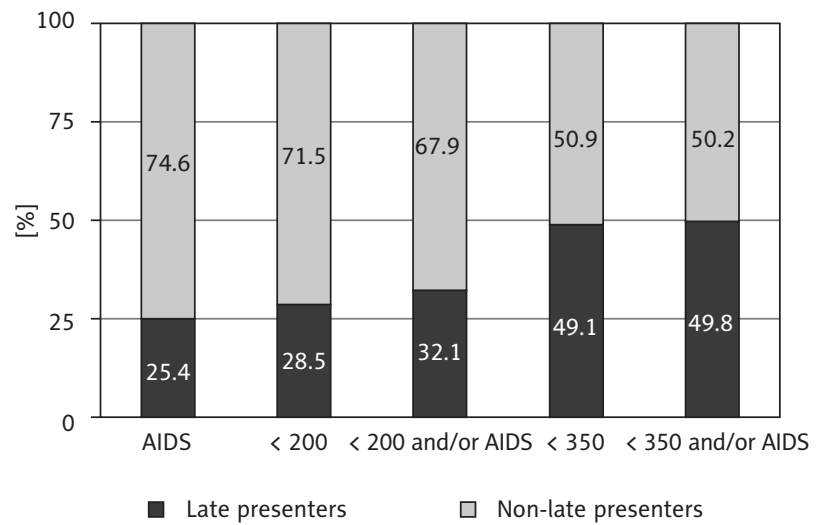

Figure 1. Different characteristics of analyzed population according to accepted definition

recent definition was applied (Table 2). This describes late presentation as CD4 T cell count below 350 cells/ $\mu$ land/or clinical CDC category C (AIDS-defining disease diagnosed) (Table 2).

According to the current definition, the groups with the highest rate of late presentation were IDUs (59.2\%) and Hxs (60.7\%). Late presentation was also more frequent among female patients (55\%) than among males (48\%).

In addition, $12 \%$ of "very late testers" were identified. These were persons with CD4 T cell count under $50 \mathrm{cell} / \mu \mathrm{l}$ at HIV diagnosis. In the IDU group the frequency of "very late testers" was $17 \%$ while that among persons infected via the heterosexual route was $15.3 \%$ and for MSM it was $7.4 \%$. The frequency of very late presenting females was $15.3 \%$ while for males it was $11.3 \%$. Statistically significant differences in the frequencies were found for all late presenting definitions between groups of IVDUs and heterosexually infected persons vs. MSM ( $p<0.05$ for all comparisons).

Patients diagnosed with clinical category A were significantly younger (median 29.8; IQD 25.4-36.5 years) than those with categories B and C (median 34.3, IQD 29-39.9 years and 35.2, IQD 30-43.9 years), respectively - differences $\mathrm{A}$ vs. B and A vs. C were statistically significant, $p<0.001$. The same tendency was observed for all "late presenter" definitions, and patients diagnosed late were significantly older than those who presented earlier for diagnosis Table 1.

Data on HIV viral load was available for 792 out of 1132 patients $(70 \%)$. As was suspected, medium viral load was significantly higher in late presenting group of patients regardless of definition ( $p<0.05$ for all) (Table 1).

Age, higher viral load, intravenous drug use, and heterosexuality were all predictors of late presenting according to current definition: IDUs vs. MSM - OR (odds ratio) 2.17 (95\% CI: 1.6-3.0), Hx vs. MSM - OR 2.1 (95\% CI: 1.5-2.0), age $\mathrm{OR}=1.07$ (95\% CI: $1.05-1.08)$ for 1 year of age $(p<0.001$ for all). For advanced stage of HIV disease (CD4 $<200$ cells/ $\mu$ l and $\mathrm{C}$ category of disease) female sex was also a predictor $(\mathrm{OR}=1.49, p=0.01)$. Multivariate logistic analysis showed that age, heterosexuality and intravenous drug use were independent predictors of late presenting regardless of definition (Table 3). Additionally, for advanced HIV-disease and AIDS diagnosis (category $\mathrm{C}$ of HIV disease) unknown route of infection was also a predictor. However multivariate regression analysis revealed that elder age was an independent factor influencing lower CD4 T cell count and late presentation. Multivariate logistic analysis showed that age, heterosexuality, and intravenous drug use are independent predictors of late presenting regardless of definition (Table 3 ).

In univariate analysis female sex, increased age, higher viral load, and intravenous drug use were risk factors for lower CD4 T cell counts $(p=0.02, p<0.001, p<0.001$, $p=0.005)$. However, the multivariate regression analysis revealed that increased age was independently related to the lower CD4 T cell count $(p<0.001)$ in males with a history of IDU $(p=0.003)$.

\section{Discussion}

Primarily, it is worth underlying the fact that in the presented study almost half of the patients were considered late presenters according to the European Late Presenter Consensus Working Group. This recent universal European definition considers a person presenting with CD4 T cell count less than 350 cells/ $\mu$ l and/or AIDS defining event, regardless of CD4 $\mathrm{T}$ cell count as being a late presenter, and an individual with an advanced HIV disease as having CD4 T cell

Table 2. Frequencies of late testing in groups of different routes of infection and gender

\begin{tabular}{l|c|c|c|c|c|c}
\hline Definition & $\begin{array}{c}\text { All, } n=1132 \\
(\%)\end{array}$ & $\begin{array}{c}\text { IDUs, } n=262 \\
(\%)\end{array}$ & $\begin{array}{c}\text { MSM, } n=498 \\
(\%)\end{array}$ & $\begin{array}{c}\text { Hx, } n=275 \\
(\%)\end{array}$ & $\begin{array}{c}\text { Female, } n=221 \\
(\%)\end{array}$ & $\begin{array}{c}\text { Male, } n=911 \\
(\%)\end{array}$ \\
\hline$<50$ & $137(12.1)$ & $45(17.2)$ & $37(7.4)$ & $43(15.6)$ & $34(15.3)$ & $103(11.3)$ \\
\hline Clinical category C & $287(25.4)$ & $84(32)$ & $76(15.3)$ & $91(33)$ & $62(28)$ & $225(24.7)$ \\
\hline$<200$ & $323(28.5)$ & $101(38.5)$ & $86(21.6)$ & $100(36.4)$ & $80(36.2)$ & $243(26.7)$ \\
\hline$<200$ and/or category C & $363(32.1)$ & $110(42)$ & $103(20.7)$ & $113(41.1)$ & $87(39.4)$ & $276(30.3)$ \\
\hline$<350$ & $556(49.1)$ & $153(58.3)$ & $192(38.6)$ & $165(60)$ & $122(55)$ & $434(47.6)$ \\
\hline$<350$ and/or category C & $564(49.8)$ & $155(59.2)$ & $196(39.4)$ & $167(60.7)$ & $122(55)$ & $437(48)$ \\
\hline
\end{tabular}

IDUs - injection drug user, MSM - male having sex with male, $\mathrm{Hx}$ - heterosexual contact 
Table 3. Multivariate analysis of factors influencing late presentation for different definitions of late presenters

\begin{tabular}{|c|c|c|c|c|c|c|}
\hline & $n$ & $\begin{array}{c}\text { Age }^{\#} \\
(95 \% \mathrm{Cl}, p)\end{array}$ & $\begin{array}{l}\text { Female vs. male } \\
\quad(95 \% \mathrm{Cl}, p)\end{array}$ & $\begin{array}{l}\text { IDUs vs. MSM } \\
(95 \% \mathrm{Cl}, p)\end{array}$ & $\begin{array}{l}\text { Hx vs. MSM } \\
(95 \% \mathrm{Cl}, p)\end{array}$ & $\begin{array}{l}\text { UNK vs. MSM } \\
(95 \% \mathrm{Cl}, p)\end{array}$ \\
\hline All & 1132 & & & & & \\
\hline OR for CD $4<50$ cells $/ \mu l$ & 137 & $\begin{array}{c}1.04(1.02-1.06 \\
p=0.000005)\end{array}$ & $\begin{array}{c}1.15(0.71-1.86 \\
p=0.56)\end{array}$ & $\begin{array}{c}2.44(1.5-3.97 \\
p=0.0003)\end{array}$ & $\begin{array}{c}1.87(1.1-3.19 \\
p=0.02)\end{array}$ & $\begin{array}{c}1.37(0.67-2.8 \\
p=0.38)\end{array}$ \\
\hline $\begin{array}{l}\text { OR for C category } \\
\text { of HIV infection }\end{array}$ & 287 & $\begin{array}{c}1.06(1.04-1.07 \\
p=0.000000)\end{array}$ & $\begin{array}{c}0.89(0.6-1.3 \\
p=0.54)\end{array}$ & $\begin{array}{c}2.72(1.87-3.97 \\
p=0.000000)\end{array}$ & $\begin{array}{l}2.55(1.7-3.83 \\
p=0.000007)\end{array}$ & $\begin{array}{c}2.69(1.62-4.45 \\
p=0.0001)\end{array}$ \\
\hline OR for CD4 $<200$ cells $/ \mu l$ & 323 & $\begin{array}{c}1.06(1.05-1.08 \\
p=0.000000)\end{array}$ & $\begin{array}{c}1.26(0.87-1.83 \\
p=0.23)\end{array}$ & $\begin{array}{c}2.83(1.97-4.06 \\
p=0.000000)\end{array}$ & $\begin{array}{c}2.16(1.42-3.15 \\
p=0.0002)\end{array}$ & $\begin{array}{c}2.13(1.3-3.52 \\
p=0.003)\end{array}$ \\
\hline $\begin{array}{l}\text { OR for } C D 4<200 \text { cells } / \mu \mathrm{l} \\
+C \text { category }\end{array}$ & 363 & $\begin{array}{c}1.06(1.05-1.08 \\
p=0.000000)\end{array}$ & $\begin{array}{c}1.19(0.82-1.72 \\
p=0.35)\end{array}$ & $\begin{array}{c}2.64(1.86-3.75 \\
p=0.000000)\end{array}$ & $\begin{array}{c}2.13(1.45-3.13 \\
p=0.0001)\end{array}$ & $\begin{array}{c}1.77(1.08-2.9 \\
p=0.02)\end{array}$ \\
\hline OR for CD4 $<350$ cells $/ \mu l$ & 556 & $\begin{array}{c}1.06(1.05-1.08 \\
p=0.00000)\end{array}$ & $\begin{array}{c}1.04(0.73-1.5 \\
p=0.82)\end{array}$ & $\begin{array}{c}2.15(1.55-2.99 \\
p=0.000005)\end{array}$ & $\begin{array}{c}2.07(1.44-2.98 \\
p=0.000096)\end{array}$ & $\begin{array}{c}1.08(0.68-1.72, \\
p=0.75)\end{array}$ \\
\hline $\begin{array}{l}\text { OR for } C D 4<350 \text { cells } / \mu \mathrm{l} \\
+C \text { category }\end{array}$ & 564 & $\begin{array}{c}1.07(1.05-1.08 \\
p=0.000000)\end{array}$ & $\begin{array}{c}1.004(0.7-1.45 \\
p=0.99)\end{array}$ & $\begin{array}{c}2.17(1.56-3.02 \\
p=0.000004)\end{array}$ & $\begin{array}{l}2.1(1.45-2.03 \\
p=0.000078)\end{array}$ & $\begin{array}{c}1.03(0.7-1.45 \\
p=0.9)\end{array}$ \\
\hline
\end{tabular}

\#OR-peryear

IDUs - injection drug user, MSM - male having sex with male, Hx - heterosexual contact, UNK - unknown/other

count below 200 and/or AIDS-defining event regardless of CD4 T cell count [12].

Thus, we are facing a situation where half of the newly diagnosed patients in the years 2006-2008 were not able to fully profit from HAART, as recommended by European and Polish guidelines for treatment [16, 17].

Furthermore, these data are similar to those obtained from other European countries, most often applying the $200 \mathrm{cells} / \mu \mathrm{l}$ threshold as a definition of later presentation. For example, a large Swiss cohort study revealed that about $30 \%$ of patients diagnosed with CD4 T cell count below 200 cells/ $\mu \mathrm{l}$ and even $10 \%$ with below 50 cells/ $\mu$ [ [18]. The factors associated with late diagnosis in the Swiss study were increased age and non-Caucasian race, in line with observations from northern France and Brussels, Belgium [19]. The second factor with its potential implication can be excluded in regard of the presented population since only the Caucasian patients were evaluated. Polish society is relatively homogenic, so single cases of non-Caucasian and foreign patients were excluded from the analysis. Italian data from Modena show 39\% late presenters among individuals diagnosed between 1992 to 2006 without a tendency to decrease [20]. In a Barcelona survey, independent risk factors for $56 \%$ of late presenters were increased age, heterosexual male gender, intravenous drug use, and being born in South America or sub-Saharan Africa [21]. United Kingdom researchers observed a higher percentage (48\%) of late presenters among people aged 50 years and over compared with $33 \%$ among younger individuals [22]. Reports from Croatia and Denmark concur with our observation that a significantly higher proportion of heterosexual patients than homosexuals are late presenters $[23,24]$.

At the start of the HIV epidemic in Poland, it was clear that injecting-drug-users were driving the spread of illness.
A group of the highest risk of infection was the group of IDUs. Nowadays the incidence of HIV acquisition by using drugs intravenously has decreased significantly. This change has taken place due to the implementation of harm-reduction programs such as needle and syringe exchange or free needle and syringe distribution and opiate substitution programs, e.g. methadone programs [25]. It seems worth noting that types of drugs were also changed during the past few years, from domination of "homemade" heroin to usually oral drugs.

However, with the successful needle and syringe exchange programs, most transmissions have shifted to being sexual (between men, and men and women partners). It is important to develop a clear understanding of the tested data and methods, and to constantly monitor the changes or trends in these results in order to make significant progress. Becoming familiar with the characteristics of the late presenters is essential, given that among heterosexuals, the perception of the risk of HIV disease is known to be low. This information can be used to assess the successfulness of health education campaigns.

Secondly, it is worth pointing out that in the presented study men who have sex with men were diagnosed earlier than persons infected via heterosexual contacts or via intravenous drug usage. This appears to be that the group of MSM test themselves more often and HIV infection has thus been more frequently diagnosed before HIV disease progression.

Therefore, the common opinion of homosexuals as being the highest risk group of HIV infection contributes to more frequent testing. The risk perception of heterosexuals seems to be lower, resulting in less frequent testing. This means that groups classically considered as having a low-risk of HIV might be of high risk of both HIV infection and late presentation. However, unlike "safe sex" practices, frequent testing is not a HIV preventive measure. 
Late presenters are more likely than early presenters to be diagnosed with opportunistic infections, their risk of death is higher, and their rate of immunological improvement is slower $[26,27]$. Initiation of HAART at higher CD4 T cell counts is associated with a lower frequency of antiretroviral drug resistance mutations at virological failure [28]. Late presentation $(\mathrm{CD} 4<350$ cells/ $\mu \mathrm{l})$ was found to be related with significantly higher costs, especially inpatient costs during the first year of medical care, and two-fold higher costs were observed during further treatment compared to patients presenting with CD4 T cell counts above 350 cells/ $\mu$ [11].

Moreover, ignorance of the serological status means that late presenters are likely to transmit the virus [29]. However, to present for testing requires the perception of being at risk of those potentially infected and a higher level of suspicion among clinicians of all specialties [30].

So far, several barriers impairing HIV testing have been identified, both among patients and health care providers [31-33]. Among the most important of these barriers in Poland are perception of low or no risk, fear of disclosure among patients (HIV stigma), and lack of knowledge and self-confidence among health care providers when proposing HIV testing. Therefore, it is very difficult to establish the "dark figure", the actual number of currently undiagnosed HIV positive individuals in our country.

Late presentation of HIV infected persons for care seems to be a universal problem in Europe [4], despite significant and constant progress in health care. Therefore, HIV testing policies and practices should be thoroughly analysed, adapted to local conditions, and subsequently implemented. To realise these goals the "HIV in Europe Initiative" was started. In view of the public health implications of early HIV diagnosis for reducing HIV transmission and preventing late presentation, HIV testing should be more frequently offered in all health care settings.

The most important issue is to find an answer to the question: Who is the person with the highest risk of presenting late?

Therefore, nowadays it is believed that the key element in the control of the HIV epidemic is the optimisation of testing for HIV. It is worth emphasising that carried-out studies like the European project HIDES 1 and 2 (HIV Indicator Disease Across Europe Study) have shown that the testing model based on the routine indicator condition-guided HIV testing, the prevalence of which in the population amounts to $>0.1 \%$, is very effective $[34,35]$.

Since May 2015 at the Emergency Department of the Hospital for Infectious Diseases in Warsaw a modern testing strategy based on the indicator conditions like mononucleosislike syndrome and pneumonia has started, surprisingly this method of testing is extremely effective, and it might be a future solution on how to diagnose at an early stage of the HIV infection.

On the basis of the presented study it seems that the most important task for the future seems to be the matter of raising people's awareness of risky behaviours. Education should be provided beginning as early as it is possible, i.e. prior to having any possibly risky contacts. Furthermore, efforts are needed to encourage HIV testing among groups not traditionally perceived as high-risk.

Nowadays, in the Department for Adults Infectious Diseases of Medical University of Warsaw and Out-Patient Clinic of the Hospital for Infectious Diseases in Warsaw, the realisation of a subsequent scientific project, aimed at the evaluation of a percentage of late presenters among patients with the HIV admitted to this unit in recent years, was commenced.

It should be noted that the characteristics of this group of persons will most likely enable the introduction of effective methods aimed at the said group of persons in the future. It seems to be clear that the awareness of transmission trends lets us find and understand an effective way to reach the groups at the highest risk of late presentation.

\section{Conclusions}

1. Almost $50 \%$ of patients were diagnosed late, after the optimal time to start HAART, in the years 2006-2008 in Poland.

2. Increased age and being a male intravenous drug user were risk factors for lower CD4 T cell count and late presentation.

3. MSMs were diagnosed much earlier in the course of HIV infection, but heterosexuals are at risk of late diagnosis and AIDS-defining disease occurrence.

\section{Conflict of interest}

The authors declare no potential conflicts of interest with respect to the research, authorship, and/or publication of this article.

\section{References}

1. Reekie J, Kowalska JD, Karpov I, et al. Regional differences in AIDS and non-AIDS related mortality in HIV-positive individuals across Europe and Argentina: the EuroSIDA study. PLoS One 2012; 7: e41673.

2. Dokuzoguz B, Korten V, Gokengin D, et al. Transmission route and reasons for HIV testing among recently diagnosed HIV patients in HIV-TR cohort, 2011-2012. J Int AIDS Soc 2014; 17 (4 Suppl 3): 19595.

3. Antiretroviral Therapy Cohort Collaboration. Life expectancy of individuals on combination antiretroviral therapy in high-income countries: a collaborative analysis of 14 cohort studies. Lancet 2008; 372: 293-299.

4. Battegay M, Fehr J, Fluckiger U, Luigia E. Antiretroviral therapy of late presenters with advanced stage of disease. J Antimicrob Chemother 2008; 62: 41-44.

5. Moreno S, Mocroft A, Monforte A. Medical and societal consequences of late presentation. Antivir Ther 2010; 15 Suppl 1: 9-15.

6. Waters L, Fisher M, Anderson J, et al.; UK CHIC Steering Committee. Responses to highly active antiretroviral therapy and clinical events in patients with a low CD4 cell count: late presenters vs. late starters. HIV Med 2011; 12: 289-298.

7. Brenner BG, Roger M, Routy JP, et al.; Quebec Primary HIV Infection Study Group. High rates of forward transmission events after acute/early HIV-1 infection. J Infect Dis 2007; 195: 951-959. 
8. Adler A, Mounier-Jack S, Coker RJ. Late diagnosis of HIV in Europe: definitional and public health challenges. AIDS Care 2009; 21: 284-293.

9. Girardi E, Sabin CA, Monforte AD. Late diagnosis of HIV infection: epidemiological features, consequences and strategies to encourage earlier testing. Acquir Immune Defic Syndr 2007; 46 Suppl 1: S3-8.

10. Fleishman JA, Yehia BR, Moore RD, Gebo KA; HIV Research Network. The economic burden of late entry into medical care for patients with HIV infection. Med Care 2010; 48: 1071-1079.

11. Krentz HB, Gill MJ. The Direct Medical Costs of Late Presentation $(<350 / \mathrm{mm})$ of HIV Infection over a 15-Year Period. AIDS Res Treat 2012; 2012: 757135 .

12. Antinori A, Coenen T, Costagiola D, et al.; European Late Presenter Consensus Working Group. Late presentation of HIV infection: a consensus definition. HIV Med 2011; 12: 61-64.

13. Werbińska-Sienkiewicz B, Rosińska M, Furman S. HIV and AIDS in Poland in 2009. Przegl Epidemiol 2011; 65: 289-295.

14. Werbińska-Sienkiewicz B, Staszewska E, Rosińska M. HIV and AIDS in Poland in 2008. Przegl Epidemiol 2010; 64: 265-271.

15. Anon. 1993 Revised Classification System for HIV Infection and Expanded Surveillance Case Definition for AIDS Among Adolescents and Adults. Available from http://www.cdc.gov/mmwr/preview/mmwrhtml/00018871.htm.

16. European AIDS Clinical Society Guidelines V6. Availabale from http://www.europeanaidsclinicalsociety.org/Guidelines/index.htm

17. Horban A, Podlasin R, Cholewińska G, et al. Principles of HIV patients care. Guidelines of Polish Scientific Society AIDS. EkoPress, Bialystok 2011; 405 [In Polish].

18. Wolbers M, Bucher HC, Furrer H, et al.; Swiss HIV Cohort Study. Delayed diagnosis of HIV infection and late initiation of antiretroviral therapy in the Swiss HIV Cohort Study. HIV Med 2008; 9: 397-405.

19. Ndiaye B, Salleron J, Vincent A, et al. Factors associated with presentation to care with advanced HIV disease in Brussels and Northern France: 1997-2007. BMC Infect Dis 2011; 11: 11.

20. Borghi V, Girardi E, Bellelli S, et al. Late presenters in an HIV surveillance system in Italy during the period 1992-2006. J Acquir Immune Defic Syndr 2008; 49: 282-286.

21. de Olalla PG, Mazardo C, Sambeat MA, et al.; the HIV Surveillance Group. Epidemiological characteristics and predictors of late presentation of HIV infection in Barcelona (Spain) during the period 2001-2009. AIDS Res Ther 2011; 8: 22.

22. Smith RD, Delpech VC, Brown AE, et al. HIV transmission and high rates of late diagnoses among adults aged 50 years and over. AIDS 2010; 24: 2109-2115.

23. Begovac J, Gedike K, Lukas D, et al. Late presentation to care for HIV infection in Croatia and the effect of interventions during the Croatian Global Fund Project. AIDS Behav 2008; 12 (4 Suppl): S48-53.

24. Leutscher PD, Laursen T, Andersen B, et al. HIV late presenters in Denmark: need for increased diagnostic awareness among general practitioners. Dan Med Bull 2011; 58: 4253-4257.

25. http://www.emcdda.europa.eu/country-data/harm-reduction/ Poland

26. Iwuji CC, Churchill D, Gilleece Y, et al. Older HIV-infected individuals present late and have a higher mortality: Brighton, UK cohort study. BMC Public Health 2013; 13: 397.

27. May M, Sterne JA, Sabin C, et al.; Antiretroviral Therapy (ART) Cohort Collaboration. Prognosis of HIV-1-infected patients up to 5 years after initiation of HAART: collaborative analysis of prospective studies. AIDS 2007; 21: 1185-1197.

28. Uy J, Armon C, Buchacz K, et al.; HOPS Investigators. Initiation of HAART at higher CD4 cell counts is associated with a lower frequency of antiretroviral drug resistance mutations at virologic failure. J Acquir Immune Defic Syndr 2009; 51: 450-453.
29. Adults and Adolescents Guidelines. Guidelines for the Use of Antiretroviral Agents in HIV-1-Infected Adults and Adolescents. U.S. Department of Health and Human Services (DHHS). Available from http://www.aidsinfo.nih.gov/guidelines/GuidelineDetail.aspx?MenuItem=Guidelines\&Search=Off\&GuidelineID=7\&ClassID=1

30. Keusch GT, Wilentz J, Kleinman A. Stigma and global health: developing a research agenda. Lancet 2006; 367: 525-527.

31. Yazdanpanah Y, Lange J, Gerstoft J, et al. Earlier testing for HIV-how do we prevent late presentation? Antivir Ther 2010; 15 Suppl 1: 17-24.

32. Dowson L, Kober C, Perry N, et al. Why some MSM present late for HIV testing: a qualitative analysis. AIDS Care 2012; 24: 204-209.

33. Lazarus JV, Jürgens R, Weait $M$, et al. Overcoming obstacles to late presentation for HIV infection in Europe. HIV Med 2011; 12: 246-249.

34. HIDES: Indicator Diseases across Europe Study. Retrieved from http://newsite.hiveurope.eu/Ongoing-Projects/HIDES

35. Raben D, Mocroft A, Rayment M, et al. Auditing HIV Testing Rates across Europe: Results from the HIDES 2 Study. PLoS One 2015; 10: $\mathrm{e} 0140845$. 